\title{
Intoxication after Extreme Oral Overdose of Quetiapine to Attempt Suicide: Pharmacological Concerns of Side Effects
}

\author{
C. Müller, ${ }^{1}$ H. Reuter, ${ }^{2}$ and C. Dohmen ${ }^{3,4}$ \\ ${ }^{1}$ Institute of Pharmacology, University of Cologne, Gleuelerstr. 24, 50931 Cologne, Germany \\ ${ }^{2}$ Department III of Internal Medicine, University of Cologne, Kerpenerstr. 62, 50937 Cologne, Germany \\ ${ }^{3}$ Max Planck Institute for Neurological Research, Gleuelerstr. 50, 50931 Cologne, Germany \\ ${ }^{4}$ Department of Neurology, University of Cologne, Gleuelerstr. 50, 50931 Cologne, Germany \\ Correspondence should be addressed to C. Müller, c.mueller@uni-koeln.de
}

Received 17 October 2009; Accepted 23 November 2009

Recommended by Rade B. Vukmir

\begin{abstract}
Quetiapine is an atypical antipsychotic approved for the treatment of patients with psychotic disorders. Since approvement several case reports about intoxication with quetiapine were linked mainly with tachycardia, $\mathrm{QT}_{\mathrm{c}}$-prolongation, somnolence, and hyperglycemia. Here, we present the first case report of an intoxication with an extreme overdose of quetiapine (36g), ingested by a 32 -year-old female $(62 \mathrm{~kg}$ bodyweight) to attempt suicide. Symptoms associated with intoxication were coma without arterial hypotension, persistent tachycardia, hyperglycemia, and transient hypothyreoidism. $\mathrm{QT}_{\mathrm{c}}$-interval was moderately extended. Management consisted of intubation for airway protection, gastric lavage, the use of activated charcoal, i.v. saline, and observation for 17 hours on an intensive care unit. Despite the extremely high dose of quetiapine, the patient recovered completely without residual symptoms.
\end{abstract}

Copyright ( $) 2009$ C. Müller et al. This is an open access article distributed under the Creative Commons Attribution License, which permits unrestricted use, distribution, and reproduction in any medium, provided the original work is properly cited.

\section{Introduction}

Quetiapine is indicated and approved for the treatment of psychotic disorders in adults by the U.S. Food and Drug Administration. The efficacy of quetiapine in the treatment of acute mania and depression associated with bipolar disorder and the therapy of schizophrenia with quetiapine has been proved in randomized controlled trials (for review, see [1]).

Pharmacokinetics and pharmacodynamics of quetiapine fumarate (Seroquel), a dibenzothiazepine antipsychotic agent bearing structural similarity to clozapine and olanzapine, have previously been described and reviewed [24]. After oral administration the drug is eliminated with a mean terminal half-life of approximately 7 hours [1]. The volume of distribution and total protein binding is $101 / \mathrm{kg}$ and $83 \%$, respectively (Prod. Info Seroquel, 2004a). The drug is primarily metabolized by sulfoxidation and oxidation with the CYP3A4 isoenzyme and the 7-hydroxylated as well as the N-dealkylated metabolite are pharmacologically active [2].
Quetiapine shows affinity for multiple neurotransmitter receptors in in vitro binding studies. The drug exhibits high affinity for serotonergic $5-\mathrm{HT}_{2 \mathrm{~A}}$-receptors and moderate affinity for dopamine $\mathrm{D}_{2}$-receptors; whereas antagonism of $\mathrm{D}_{1}$ - and $5-\mathrm{HT}_{1 \mathrm{~A}}$-receptors is relatively weak. The antipsychotic effect is explained by the antagonistic effect on $\mathrm{D}_{2}$ receptors and 5- $\mathrm{HT}_{2 \mathrm{~A}}$-receptors [5].

Appreciable affinity for $\alpha_{1}$-adrenergic, $\alpha_{2}$-adrenergic, and histamine $\mathrm{H}_{1}$-receptors has also been observed [6].

Adverse effects even at the beginning of the therapy like sedation and somnolence are explained by antagonism of histamine $\mathrm{H}_{1}$-receptors. Orthostatic dysregulation, hypotension, and tachycardia are associated with an antagonistic effect on $\alpha_{1}$-adrenergic receptors. Quetiapine has also been reported to have an antagonistic effect on $\mathrm{M}_{1}$-muscarinic receptors resulting in anticholinergic mediated tachycardia $[1,7]$.

Quetiapine and other atypical antipsychotic drugs like clozapine or olanzapine provide antipsychotic efficacy with a lower risk of EPS compared to typical antipsychotics, but atypical antipsychotics are associated with a variety 
of metabolic and cardiovascular adverse effects particularly with regard to an overdose [8-15]. If treating patients with quetiapine one should be familiar with the clinical symptoms of quetiapine intoxication and its treatment. Here, we report on clinical effects of an extreme quetiapine overdose and how such an intoxication can be survived under appropriate treatment.

\section{Case Report}

We report on a 32-year-old female (62 kg bodyweight) with history of paranoid-hallucinatory schizophrenia and depression who was discovered by her companion in life 26 hours after ingestion of $36 \mathrm{~g}$ quetiapine (120 tablets of $100 \mathrm{mg}$ and 80 tablets of $300 \mathrm{mg}$ ) and a suspected abuse of lorazepam. A previous suicide had been attempted 10 years before with haloperidol. Her past medical history was negative for cardiac dysrhythmia, hypertensive heart disease or a thyroid dysfunction. The emergency medical service found the patient comatose with response only to deep painful stimuli (Glasgow Coma Scale of 9), normotensive $(127 / 83 \mathrm{mmHg})$, hyperglycemic capillary glucose level: $8.96 \mathrm{mmol} / \mathrm{L}=160 \mathrm{mg} / \mathrm{dl}$ and tachycardiac with sinustachycardia of $140 \mathrm{bpm}$, capillary oxygen saturation was $98 \%$ and respiratory rate $12 / \mathrm{min}$. There was no evidence of trauma or infection. During the transport to the hospital $40 \mathrm{mg}$ of furosemide and $1000 \mathrm{~mL}$ saline were administered intravenously for detoxification and prophylaxis of hypotension. Vital signs were stable during transport.

On admission on the intensive care unit (ICU) the patient's condition worsened and she was intubated for airway protection. At this time venous blood gas on $30 \%$ $\mathrm{FiO}_{2}$ revealed $\mathrm{pH}$ of $7.38, \mathrm{pO}_{2}$ of $45.3 \mathrm{mmHg}, \mathrm{pCO}_{2}$ $42.2 \mathrm{mmHg}, \mathrm{HCO}_{3}^{-} 24.4 \mathrm{mmol} / \mathrm{L}$, base excess $-0.1 \mathrm{mmol} / \mathrm{L}$, $\mathrm{Hb} 13.8 \mathrm{~g} / \mathrm{dl}, \mathrm{K}^{+} 3,7 \mathrm{mmol} / \mathrm{L}, \mathrm{Na}^{+} 140 \mathrm{mmol} / \mathrm{L}$.

To prevent her from further absorption of quetiapine a gastric lavage was performed (no pill fragments of ingested tablets were recovered) and the patient enterally received $25 \mathrm{~g}$ of activated charcoal with $5 \mathrm{~g}$ Glauber's salt (sodium sulfate) every 3 to 4 hours until dejection of black stool.

Laboratory data on admission including serum electrolytes, liver, and renal function parameters and blood count remained normal except glucose of $8.12 \mathrm{mmol} / \mathrm{L}$ $(145 \mathrm{mg} / \mathrm{dl})$, CK of $333 \mathrm{U} / \mathrm{L}$ (control value remained unchanged) with no evidence of myocardial insufficiency or infarction, CRP of $32 \mathrm{mg} / \mathrm{L}$ (control value 8 hours later increased to $76 \mathrm{mg} / \mathrm{L}$ ), TSH $6.0 \mathrm{mU} / \mathrm{L}$ (control value 8 hours later increased to $8.56 \mathrm{mU} / \mathrm{L}$ ), and leucocytosis with 12.06 $\left(\times 10^{9} / \mathrm{L}\right)$.

The electrocardiogram at 36 hours postingestion revealed a moderately extended $\mathrm{QT}_{\mathrm{c}}$ interval measuring 436 millisseconds (at the upper limit of normal) compared to $\mathrm{QT}_{\mathrm{c}}$ interval of $388 \mathrm{~ms}$ after complete recovery. $\mathrm{QT}_{\mathrm{c}}$-intervals were calculated using the Bazett formula [16].

A comprehensive drug screen via immunoassay was positive for tricyclic antidepressants and benzodiazepines in particular, although these results could not be confirmed by UV-HPLC-methods.

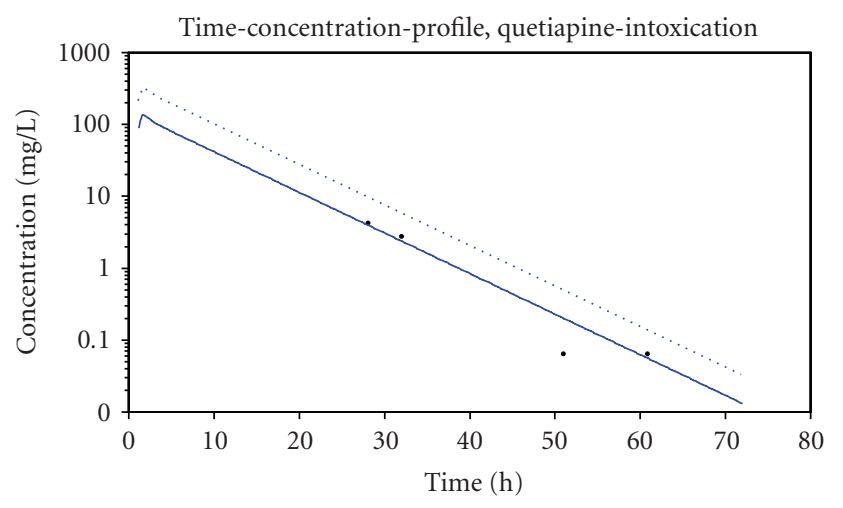

FIgURE 1: Serum time-concentration profile of quetiapine after ingestion of an assumed amount of $36 \mathrm{~g}$ Seroquel in a 32-year-old female patient. Solid-line: fitted line based on a two-compartment model assuming a reduced resorption. Dotted line: fitted line expected by population pharmacokinetic parameters and normal resorption.

One day after admission cardiac and pulmonary status was stable (without signs of $\mathrm{QT}_{\mathrm{c}}$-prolongation, arrhythmia, or tachycardia), state of consciousness improved, so that she could be extubated and was transferred to psychiatric crisis ward within 67 hours after ingestion of quetiapine. The increased levels for glucose and TSH lasted for 2.5 days, CK turned to normal after 6 days and CRP after roughly two weeks, respectively (see Table 1 ).

Serum-samples for pharmacokinetic analysis were collected directly on arrival in the emergency department, 5 hours after admission and the following two days (four samples in total). Quetiapine serum concentrations were determined by a validated UV-HPLC-method (linearity range $0.03-4.00 \mathrm{mg} / \mathrm{L}$, lower limit of quantification (LLOQ) $0.03 \mathrm{mg} / \mathrm{L}$, limit of detection (LOD) $0.01 \mathrm{mg} / \mathrm{L}$ ). Drug concentrations and patient's data (gender, age, weight, height) as well as the ingested amount of quetiapine were processed by a commonly used pharmacokinetic program Mw/Pharm 3.50 [17]. Pharmacokinetic parameters were investigated based on an open two-compartment model and a Bayesian fitting procedure.

Elimination half-life was calculated as follows:

$-t_{1 / 2}=\ln 2 / \lambda_{\mathrm{z}}$ (elimination, $\lambda_{\mathrm{z}}$ is the rate constant corresponding to the terminal elimination).

Figure 1 exemplifies the obtained quetiapine concentration levels and the software generated time-concentration profile based on a two-compartment model (solid-line). In addition, the expected time-concentration profile based on population-pharmacokinetic data is shown (dotted line). Absorption was supposed to be reduced because of anticholinergic effects of quetiapine on intestinal tract.

The elimination half-life was $t_{1 / 2}=5.3$ hours and was calculated based on the four obtained quetiapine concentration levels $\left(c_{1}=4.22 \mathrm{mg} / \mathrm{L} ; c_{2}=2.77 \mathrm{mg} / \mathrm{L} ; c_{3}=\right.$ $\left.0.06 \mathrm{mg} / \mathrm{L} ; c_{4}=0.06 \mathrm{mg} / \mathrm{L}\right)$ with regard to patient's medical records and displayed a moderately increased elimination 
TABLE 1

\begin{tabular}{|c|c|c|c|c|c|c|c|c|c|}
\hline \multirow{2}{*}{ Parameter } & \multicolumn{9}{|c|}{ Time after ingestion of quetiapine } \\
\hline & $26 \mathrm{~h}$ & $28 \mathrm{~h}$ & $29 \mathrm{~h}$ & $32 \mathrm{~h}$ & $37 \mathrm{~h}$ & 51 & $62 \mathrm{~h}$ & $140 \mathrm{~h}$ & $331 \mathrm{~h}$ \\
\hline \multicolumn{10}{|l|}{ Laboratory data: } \\
\hline Quetiapine, $\mu \mathrm{g} / \mathrm{L}$ & & 4220 & & 2770 & & 64 & 64 & & \\
\hline $\mathrm{Na}^{+}, \mathrm{mmol} / \mathrm{L}$ & & & 137 & & 140 & & 141 & 138 & 138 \\
\hline $\mathrm{K}^{+}, \mathrm{mmol} / \mathrm{L}$ & & & 3.6 & & 4.6 & & 4.0 & 3.6 & 4.3 \\
\hline $\mathrm{Cl}^{-}, \mathrm{mmol} / \mathrm{L}$ & & & & & 123 & & 116 & 105 & 105 \\
\hline Glucose, $\mathrm{mmol} / \mathrm{L}$ & 8.96 & & 8.12 & & 5.94 & & 5.04 & 5.66 & 5.49 \\
\hline $\mathrm{CK}, \mathrm{U} / \mathrm{L}$ & & & 333 & & 317 & & 355 & 69 & 66 \\
\hline Leucocytes $\left(\times 10^{9} / \mathrm{L}\right)$ & & & 12.06 & & 6.61 & & 6.23 & 6.21 & 5.46 \\
\hline $\mathrm{CRP}, \mathrm{mg} / \mathrm{L}$ & & & 32 & & 76 & & 96 & 11 & $<3$ \\
\hline Free T3, ng/L & & & 2.8 & & 2.1 & & 2.6 & & \\
\hline Free T4, ng/L & & & 18.6 & & 14.1 & & 12.0 & & \\
\hline $\mathrm{TSH}, \mathrm{mU} / \mathrm{L}$ & & & 6.04 & & 8.56 & & 3.35 & & \\
\hline \multicolumn{10}{|l|}{ Vital parameters: } \\
\hline BP syst., mmHg & 127 & & 110 & & 120 & & 130 & 130 & \\
\hline BP diast., mmHg & 83 & & 70 & & 80 & & 70 & 70 & \\
\hline HR, beats/min & 140 & & 120 & & 90 & & 85 & 85 & \\
\hline $\mathrm{RR}$, resp./min & 12 & & 12 & & 8 & & 8 & & \\
\hline QTc $[\mathrm{ms}]$ & & & & & 436 & & 404 & & 388 \\
\hline
\end{tabular}

CK: creatin kinase, CRP: c-reactive protein, T3: triiodothyronine, T4: tetraiodothyronine, TSH: thyroid-stimulating hormone, BP: blood pressure, HR: heart rate, RR: respiratory rate, QTc: cardiac QT interval (at a standardized heart rate of 60/minute).

compared to population pharmacokinetic parameters. Additionally, the absorption rate constant $\mathrm{k}_{\mathrm{a}}$ (time $)^{-1}$ had to be adjusted and displayed a reduced absorption of quetiapine after ingestion. In this case the patient was supposed to have ingested $36 \mathrm{~g}$ quetiapine corresponding to a dosage of $580 \mathrm{mg} / \mathrm{kg}$ quetiapine. Volume of distribution was within the expected range $\left(V_{d}=9 \mathrm{~L} / \mathrm{kg}\right.$ based on fitted solid line, Figure 1).

Expected peak quetiapine concentrations for populationpharmacokinetic data were higher than the fitted timeconcentration profile based on measured quetiapine concentrations and a two-compartment model.

\section{Discussion}

This is the first case report of an intoxication with such an extremely high amount of quetiapine $(580 \mathrm{mg} / \mathrm{kg})$. Remarkable side effects were tachycardia, somnolence, hyperglycemia, transient hypothyroidism, and a moderately prolonged $\mathrm{QT}_{\mathrm{c}}$-interval, but the patient survived and fully recovered.

Side effects: tachycardia is most likely explained by an anticholinergic effect of quetiapine [7].

Symptoms of central nervous depression (somnolence, drowsiness) are primarly mediated through antagonistic effect of quetiapine on serotonergic $5-\mathrm{HT}_{2 \mathrm{~A}}$ - and moderate antagonistic effect on dopamine type $2 \mathrm{D}_{2}$-receptors. Prolonged tachycardia is usually explained by an antagonistic effect of quetiapine on $\alpha_{1}$-receptors [7]. Generally, the adverse effects like tachycardia, hyotension, and somnolence associated with quetiapine in particular after ingestion of an overdose can be explained by blockage of the alphaadrenergic, muscarinic, and histamine receptors [1].

In recent publications surprisingly no statement about additional blood glucose laboratory data was provided, although several case reports after ingestion of high dosages of quetiapine were presented $[7,9]$.

The mechanism for hyperglycemia may be related to $5-\mathrm{HT}_{2}$-receptor antagonism, which is associated not only with weight gain but also with hyperglycemia $[18,19]$. 5$\mathrm{HT}_{2}$-receptor antagonists can significantly decrease insulin sensitivity, an effect possibly mediated by the suppression of $5-\mathrm{HT}_{2 \mathrm{~A}}$-receptor-mediated glucose uptake in skletal muscle $[8,20]$. For instance, $5-\mathrm{HT}_{2 \mathrm{C}}$ knockout mice develop insulin resistance and impaired glucose tolerance and show severe weight gain [21]. This may be a likely mechanism for hyperglycemia in the therapy with atypical antipsychotics and in case of quetiapine overdose.

Moreover antipsychotic drug affinity and antagonistic effects on muscarinic receptors are significant predictors of the development of diabetes. Muscarinic $\mathrm{M}_{3}$-receptors are highly expressed by pancreatic $\beta$-cells and antagonism leads to dysregulation of glucose-dependent acetylcholin modulation of insulin secretion [22].

Suppression of compensatory insulin release may explain hyperglycemia in the present case report of quetiapine overdose.

Summarized, three receptor mediated mechanisms are commonly supposed for glucosedysregulation in particular after intoxication with an atypical antipsychotic.

First, 5- $\mathrm{HT}_{2 \mathrm{~A}}$-receptor antagonism: suppression of receptor-mediated glucose uptake in skeletal muscle. 
Second, 5- $\mathrm{HT}_{2 \mathrm{C}}$-antagonism is correlated with an increased risk of diabetes and weight gain most likely explained by $5-\mathrm{HT}_{2 \mathrm{C}}$-receptor mediated insulin resistence and impaired glucose tolerancelinebreak [21].

Third, $\mathrm{M}_{3}$-receptor-antagonism: dysregulation of glucose-dependent acetylcholin modulation of insulin secretion.

Hypothyroidism. Hypothyroidism associated with quetiapine treatment has been reported in previous studies under treatment with a normal daily dosage of quetiapine [2326]. Although the mechanism is not known a competitive metabolism of thyroid hormones and quetiapine by UDPglucoronyltransferase has been suggested as a plausible mechanism for a decrease of thyroid hormones during quetiapine treatment [25].

In case of a patient with compromised thyroid function receiving treatment with quetiapine may develop hypothyroidism and clinicians should consider routine monitoring of thyroid function [23].

Observed Quetiapine Concentrations and Pharmacokinetics. In our case report the measured serum concentrations of quetiapine were lower than the expected quetiapine concentrations due to the absorption rate constant, $\mathrm{k}_{\mathrm{a}}$ (time) $)^{-1}$ and displayed a reduced absorption of quetiapine after ingestion (Figure 1). These findings are consistent with previously findings $[11,12]$. Lower than expected peak concentrations may be explained by potential anticholinergic effects of quetiapine reducing absorption. With regard to a delayed absorption the expected time to maximum quetiapine concentration is supposed to be prolonged in these cases. In contrast to the findings of Hunfeld et al. we determined a serum time-concentration profile lower than the expected one. We assume that the impacts of side effects after ingestion of a very high amount of quetiapine may have contributed a decreased absorption with no influence on terminal elimination half-life.

With regards to the rescue case protocol the patient is supposed to have ingested $36 \mathrm{~g}$ quetiapine (rescue operation record: 120 tablets of $100 \mathrm{mg}$ and 80 tablets of $300 \mathrm{mg}$ ). Although it cannot be ruled out that the ingested amount might have been less than $36 \mathrm{~g}$, the timeconcentration profile in this case is based on reduced absorption.

In contrast to these explanations the reason for considerably lower than expected quetiapine concentrations could obviously be an ingestion of a much lower amount of about $18 \mathrm{~g}$ quetiapine.

A comprehensive drug screen via immunoassay was positive for tricyclic antidepressants and benzodiazepines in particular.

Though an additional spectrophotometric (UV)-HPLCmethod performed by the institute of forensic medicine did not confirm the concomitant intake of lorazepam.

Drug screening also was positive for tricyclic antidepressants, although the use of immunoassays is limited, because different drugs of the corresponding group may have quite different cross reactivity and/or pharmacological potency [27].

A comprehensive drug screening of tricyclic antidepressants could not be confirmed in additional analyses with UVHPLC.

Recommendations for Management of Therapy after Quetiapine Intoxication. The treatment of quetiapine intoxications in case of an unknown ingested amount in particular consists in a supportive therapy and the patients should be monitored in an intensive care unit.

Forced Diuresis with Furosemide and Saline. Although $40 \mathrm{mg}$ furosemide were administered during transport, the treatment with diuretic drugs for the purpose of enhanced elimination is no longer recommended [28]. Moreover the efficiency of this treatment is limited due to a relatively large volume of distribution of quetiapine $\left(\mathrm{V}_{\mathrm{d}}=10 \mathrm{l} / \mathrm{kg}\right)$ and a small renal elimination rate of quetiapine (less than 5\%).

In case of a hypotensive patient the administration of diuretic drugs (e.g., furosemide) is not recommended, because of worsening the patients condition (further decrease of blood pressure).

Gastric Lavage after 27 Hours. To prevent further absorption of quetiapine a gastric lavage was performed and the patient was given activated charcoal with Glauber's salt 27 hours after quetiapine ingestion according to the recommendation of Burns et al.

At this time gastrointestinal passage of quetiapine is almost completed, although charcoal and glauber's salt (sodium sulfate) should be administered as soon as possible, if lag-time of drug ingestion is unknown. It should be noted that the risk of death following atypical antipsychotic overdose is very low [13] and gastric lavage is not routinely recommended after the 60 minutes time range $[13,29]$.

Monitoring of cardiac and respiratory function, intravenous access, and a 12-lead ECG is required [7, 13, 14].

Adminstration of intravenous magnesium sulfate $(2 \mathrm{~g}$ bolus followed by an infusion of $2-4 \mathrm{mg} /$ minute) is the intial therapy of choice regardless of serum magnesium level to the patient with $\mathrm{QT}_{\mathrm{c}}$ prolongation. Serum potassium should be maintained in the high-normal range $(4.5-5 \mathrm{mmol} / \mathrm{L})$ and ingested drugs as well as interfering drugs with its metabolism have to be discontinued [30].

Monitoring of thyroid function in quetiapine treated patients with a history of or a vulnerability to thyroid disease is strongly recommended [31].

\section{Summary}

To our knowledge, the present case report is the first with an extremely high ingestion of quetiapine (36g). Symptoms associated with intoxication were coma without arterial hypotension, persistent tachycardia, hyperglycemia, transient hypothyroidism, and a moderately extended $\mathrm{QT}_{\mathrm{c}^{-}}$ interval. Management of overdose consisted in primarily supportive therapy on an intensive care unit.

In addition the present case may help us to understand the different side effects of an atypical antipsychotic drug with regard to receptor-pharmacological mechanisms. 
Therapeutic drug monitoring and pharmacokinetic analysis of quetiapine after intoxication displayed a moderately increased elimination and a reduced absorption of quetiapine.

Despite the extreme overdose of quetiapine the patient exhibited a rapid clinical improvement and recovered without residual symptoms.

\section{References}

[1] C. L. DeVane and C. B. Nemeroff, "Clinical pharmacokinetics of quetiapine: an atypical antipsychotic," Clinical Pharmacokinetics, vol. 40, no. 7, pp. 509-522, 2001.

[2] J. L. Goren and G. M. Levin, "Quetiapine, an atypical antipsychotic," Pharmacotherapy, vol. 18, pp. 1183-1194, 1998.

[3] L. F. Fabre Jr., L. Arvanitis, J. Pultz, V. M. Jones, J. B. Malick, and V. B. Slotnick, "ICI 204,636, a novel, atypical antipsychotic: early indication of safety and efficacy in patients with chronic and subchronic schizophrenia," Clinical Therapeutics, vol. 17, pp. 366-378, 1995.

[4] B. Green, "Focus on quetiapine," Current Medical Research and Opinion, vol. 15, no. 3, pp. 145-151, 1999.

[5] T. Healthcare, Intranet database, version 5.1. Micromedex ${ }^{\circledR}$ Healthcare Series, January 2006.

[6] C. F. Saller and A. I. Salama, "Seroquel: biochemical profile of a potential atypical antipsychotic," Psychopharmacology, vol. 112, no. 2-3, pp. 285-292, 1993.

[7] C. R. Balit, G. K. Isbister, L. P. Hackett, and I. M. Whyte, "Quetiapine poisoning: a case series," Annals of Emergency Medicine, vol. 42, no. 6, pp. 751-758, 2003.

[8] H. A. Nasrallah, "Atypical antipsychotic-induced metabolic side effects: insights from receptor-binding profiles," Molecular Psychiatry, vol. 13, pp. 27-35, 2007.

[9] N. G. Hunfeld, E. M. Westerman, D. J. Boswijk, J. A. de Haas, M. J. van Putten, and D. J. Touw, "Quetiapine in overdosage: a clinical and pharmacokinetic analysis of 14 cases," Therapeutic Drug Monitoring, vol. 28, pp. 185-189, 2006.

[10] A. Kamran, P. M. Doraiswamy, J. L. Jane, E. B. Hammett, and L. Dunn, "Severe hyperglycemia associated with high doses of clozapine," American Journal of Psychiatry, vol. 151, no. 9, p. 1395, 1994.

[11] E. Nudelman, L. M. Vinuela, and C. I. Cohen, "Safety in overdose of quetiapine: a case report," Journal of Clinical Psychiatry, vol. 59, no. 8, p. 433, 1998.

[12] P. T. Pollak and K. Zbuk, "Quetiapine fumarate overdose: clinical and pharmacokinetic lessons from extreme conditions," Clinical Pharmacology and Therapeutics, vol. 68, no. 1, pp. 9297, 2000.

[13] M. J. Burns, "The pharmacology and toxicology of atypical antipsychotic agents," Journal of Toxicology-Clinical Toxicology, vol. 39, no. 1, pp. 1-14, 2001.

[14] G. Catalano, M. C. Catalano, R. E. Agustines, E. M. Dolan, and K. N. Paperwalla, "Pediatric quetiapine overdose: a case report and literature review," Journal of Child and Adolescent Psychopharmacology, vol. 12, no. 4, pp. 355-361, 2002.

[15] F. M. Hustey, "Acute quetiapine poisoning," Journal of Emergency Medicine, vol. 17, no. 6, pp. 995-997, 1999.

[16] K. Hnatkova and M. Malik, "“Optimum” formulae for heart rate correction of the QT interval," Pacing and Clinical Electrophysiology, vol. 22, pp. 1683-1687, 1999.

[17] J. H. Proost and D. K. Meijer, "MW/Pharm, an integrated software package for drug dosage regimen calculation and therapeutic drug monitoring," Computers in Biology and Medicine, vol. 22, no. 3, pp. 155-163, 1992.

[18] F. Chaouloff, D. Laude, and V. Baudrie, "Effects of the 5$\mathrm{HT}(1 \mathrm{C}) / 5$-HT2 receptor agonists DOI and $\alpha$-methyl-5-HT on plasma glucose and insulin levels in the rat," European Journal of Pharmacology, vol. 187, no. 3, pp. 435-443, 1990.

[19] S. Gupta, C. Steinmeyer, B. Frank, et al., "Hyperglycemia and hypertriglyceridemia in real world patients on antipsychotic therapy," American Journal of Therapeutics, vol. 10, no. 5, pp. 348-355, 2003.

[20] M. Gilles, A. Wilke, D. Kopf, A. Nonell, H. Lehnert, and M. Deuschle, "Antagonism of the serotonin (5-HT)-2 receptor and insulin sensitivity: implications for atypical antipsychotics," Psychosomatic Medicine, vol. 67, no. 5, pp. 748-751, 2005.

[21] K. Nonogaki, A. M. Strack, M. F. Dallman, and L. H. Tecott, "Leptin-independent hyperphagia and type 2 diabetes in mice with a mutated serotonin 5-HT(2C) receptor gene," Nature Medicine, vol. 4, no. 10, pp. 1152-1156, 1998.

[22] J. S. Silvestre and J. Prous, "Research on adverse drug events. I. Muscarinic M3 receptor binding affinity could predict the risk of antipsychotics to induce type 2 diabetes," Methods and Findings in Experimental and Clinical Pharmacology, vol. 27, no. 5, pp. 289-304, 2005.

[23] B. M. Feret and C. F. Caley, "Possible hypothyroidism associated with quetiapine," Annals of Pharmacotherapy, vol. 34, no. 4, pp. 483-486, 2000.

[24] R. L. Dobbs, N. C. Brahm, G. Fast, and R. C. Brown, “Thyroid function alterations following quetiapine initiation in a developmentally disabled adolescent," Annals of Pharmacotherapy, vol. 38, no. 9, pp. 1541-1542, 2004.

[25] D. L. Kelly and R. R. Conley, "Thyroid function in treatmentresistant schizophrenia patients treated with quetiapine, risperidone, or fluphenazine," The Journal of Clinical Psychiatry, vol. 66, no. 1, pp. 80-84, 2005.

[26] S. Ramaswamy, Z. Siddiqui, S. Saharan, T. L. Gabel, and S. C. Bhatia, "Quetiapine-induced hypothyroidism," Journal of Psychiatry and Neuroscience, vol. 30, no. 1, p. 57, 2005.

[27] H. H. Maurer, "Demands on scientific studies in clinical toxicology," Forensic Science International, vol. 165, no. 2-3, pp. 194-198, 2007.

[28] A. T. Proudfoot, E. P. Krenzelok, and J. A. Vale, "Position paper on urine alkalinization," Journal of Toxicology-Clinical Toxicology, vol. 42, no. 1, pp. 1-26, 2004.

[29] J. A. Vale and K. Kulig, "Position paper: gastric lavage," Journal of Toxicology-Clinical Toxicology, vol. 42, pp. 933-943, 2004.

[30] A. Gupta, A. T. Lawrence, K. Krishnan, C. J. Kavinsky, and R. G. Trohman, "Current concepts in the mechanisms and management of drug-induced QT prolongation and torsade de pointes," American Heart Journal, vol. 153, no. 6, pp. 891899, 2007.

[31] J. Liappas, T. Paparrigopoulos, I. Mourikis, and C. Soldatos, "Hypothyroidism induced by quetiapine: a case report," Journal of Clinical Psychopharmacology, vol. 26, no. 2, pp. 208209, 2006. 


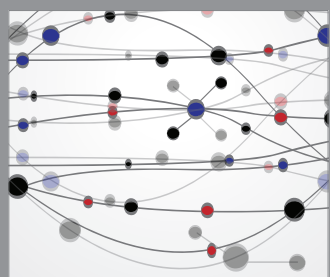

The Scientific World Journal
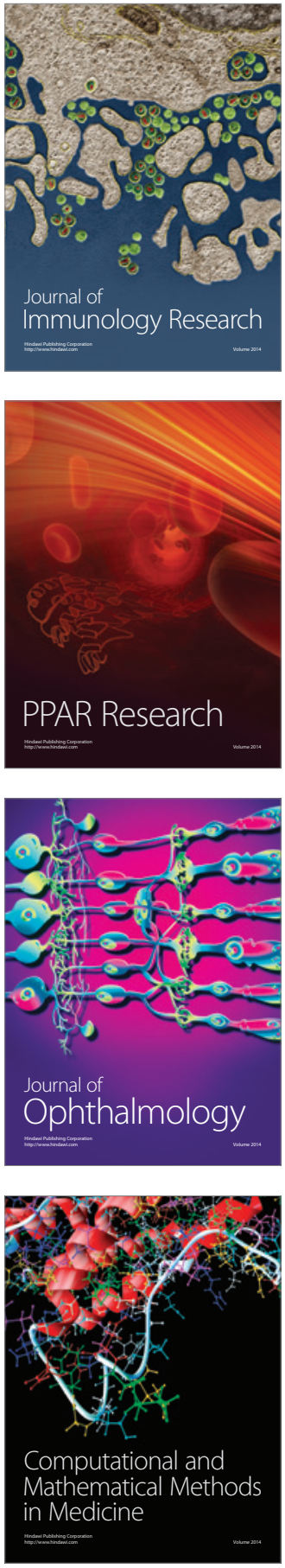

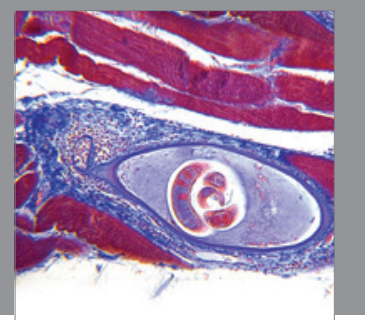

Gastroenterology

Research and Practice
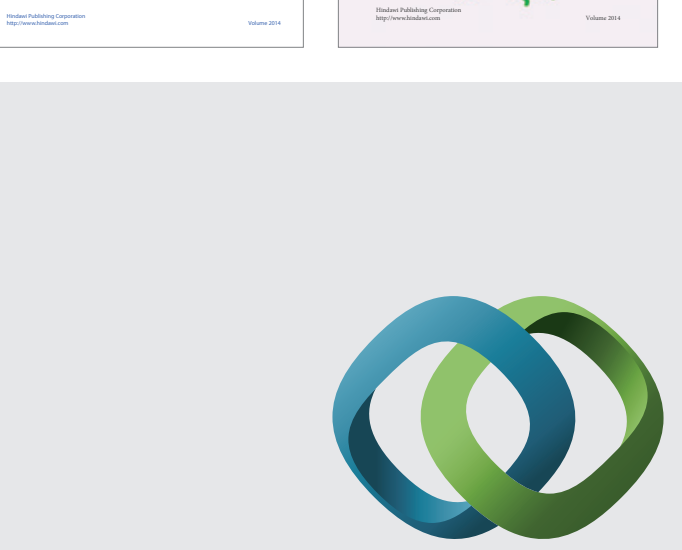

\section{Hindawi}

Submit your manuscripts at

http://www.hindawi.com
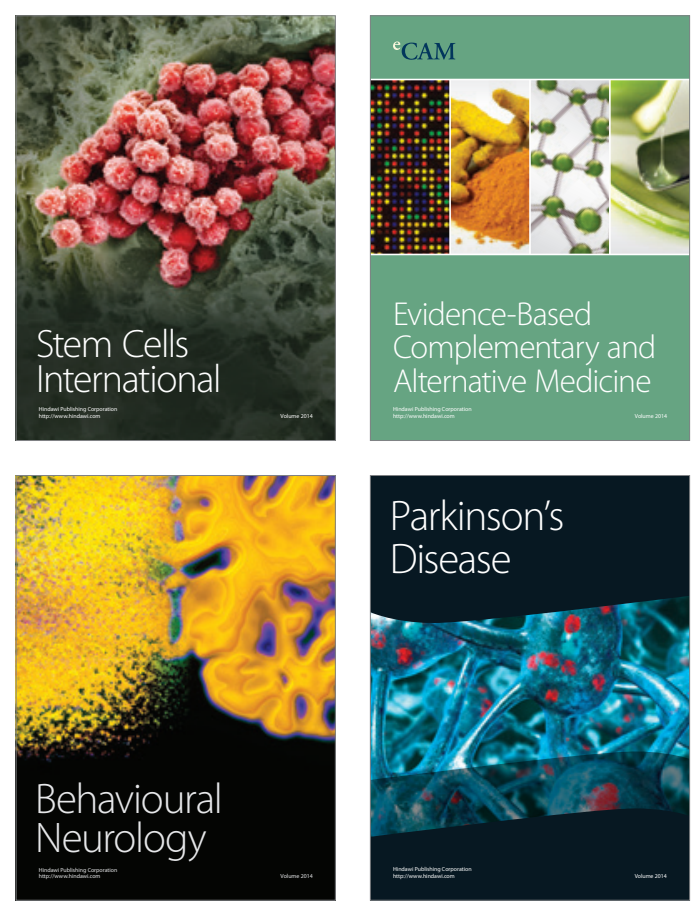

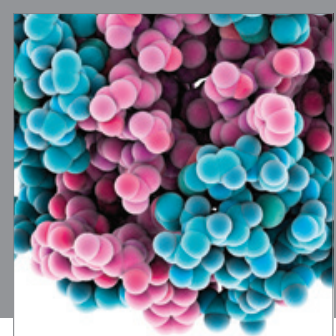

Journal of
Diabetes Research

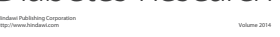

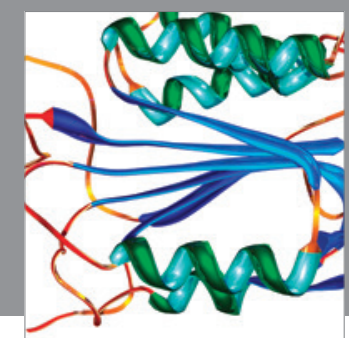

Disease Markers
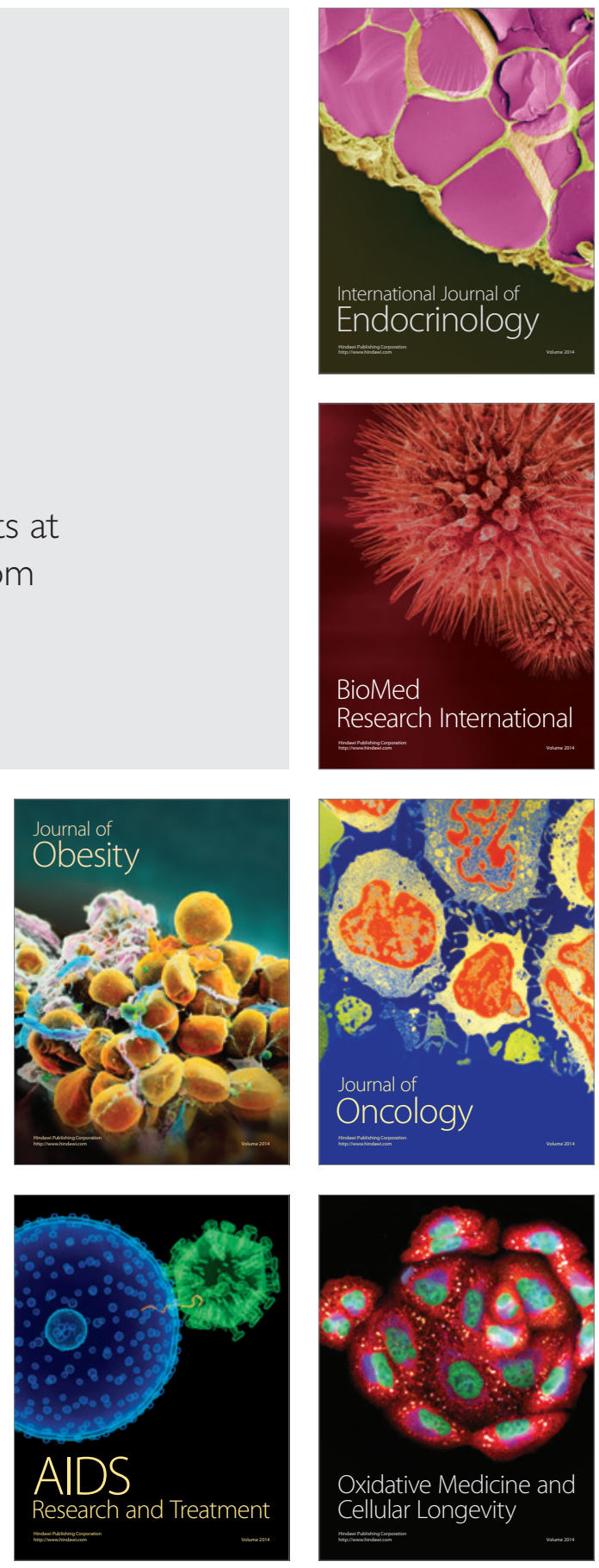